\title{
Off-pump bilateral skeletonized internal thoracic artery grafting in patients with chronic kidney disease
}

\author{
Takeshi Kinoshita, MD, PhD, Tohru Asai, MD, PhD, and Tomoaki Suzuki, MD, PhD
}

\section{ABSTRACT}

Background: We compared the outcomes in propensity score-matched patients who had chronic kidney disease (CKD) undergoing off-pump coronary bypass grafting, with either a bilateral or single skeletonized internal thoracic artery (ITA).

Methods: Of 1254 consecutive patients undergoing isolated coronary bypass surgery (1248 by the off-pump technique without emergent conversion to cardiopulmonary bypass), the 1203 who received a skeletonized, single $(n=453)$ or bilateral $(\mathrm{n}=750)$, ITA graft were enrolled, after excluding the 6 patients who received preoperative percutaneous cardiopulmonary support and the 75 who had only 1 target vessel in the left coronary area. A total of 412 pairs were matched using propensity scores. Kaplan-Meier analyses were used to assess all-cause and cardiac-related mortality, by CKD stage (assessed by glomerular filtration rate [GFR]: $<30 ; 30-60 ;>60 \mathrm{~mL} / \mathrm{minute} / 1.73 \mathrm{~m}^{2}$ ). Multivariate Cox proportional hazard models were used to assess for association of bilateral grafting with mortality. A test for interaction of bilateral ITA grafting and estimated GFR was conducted.

Results: No significant difference was found in the incidence of 30-day mortality, stroke, or deep sternal infection between the 2 groups. Although an advanced stage of CKD decreased overall survival, a benefit of bilateral ITA grafting for all-cause and cardiac-related mortality occurred relatively early in the followup period and was not influenced by CKD stage. Bilateral ITA grafting was independently associated with a lower risk of both all-cause and cardiac-related mortality in patients with an estimated GFR of $<60$. No interaction was found between bilateral ITA grafting and estimated GFR in either model.

Conclusions: In patients who have CKD, off-pump, skeletonized, left-side bilateral ITA grafting is associated with lower risk of all-cause and cardiac-related mortality, and does not increase operative risk. (J Thorac Cardiovasc Surg 2015;150:315-21)

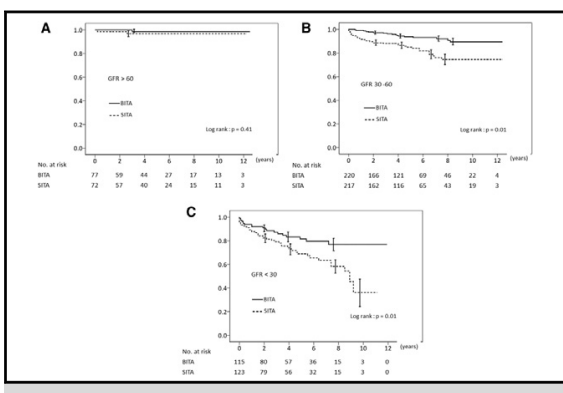

The figure shows survival, free from all-cause mortality, in the matched cohort, stratified by chronic kidney disease stage. GFR is given as $\mathrm{mL} /$ minute/ $1.73 \mathrm{~m}^{2}$. GFR, Glomerular filtration rate; BITA, bilateral internal thoracic artery; SITA, single internal thoracic artery.

\section{Central Message}

In CKD patients, off-pump, left-side, bilateral, skeletonized ITA grafts decrease risk of allcause and cardiac-related mortality.

\section{Perspective}

The issue of how to improve outcomes of patients who have CKD remains unresolved. Off-pump, skeletonized, left-side, BITA grafting is associated with lower risk of all-cause and cardiac-related mortality, and does not increase operative risk. This benefit occurred relatively early in the follow-up period and was not influenced by CKD stage.

See Editorial Commentary page 321.

\section{Supplemental material is available online.}

With the average age of the population increasing, along with the prevalence of hypertension and diabetes, more patients with chronic kidney disease (CKD) are being

\footnotetext{
From the Division of Cardiovascular Surgery, Shiga University of Medical Science, Setatsukinowa, Otsu, Japan.

Received for publication Dec 5, 2014; revisions received April 7, 2015; accepted for publication April 18, 2015; available ahead of print June 30, 2015.

Address for reprints: Takeshi Kinoshita, MD, PhD, Shiga University of Medical Science, Setatsukinowa, Otsu, 520-2192, Japan (E-mail: kinotakekinotake@yahoo.co.jp). $0022-5223 / \$ 36.00$

Copyright (c) 2015 by The American Association for Thoracic Surgery http://dx.doi.org/10.1016/j.jtcvs.2015.04.058
}

referred for coronary artery bypass surgery. In the past decade, CKD has been shown to be associated with an increased risk of mortality and adverse cardiovascular events after coronary artery bypass grafting surgery. ${ }^{1,2}$ The issue of how to improve outcomes for this patient group remains unresolved.

A survival benefit from bilateral internal thoracic artery (BITA) grafting, compared with single internal thoracic artery (SITA) grafting, has been demonstrated over the past few decades. To date, however, few studies have examined clinical outcomes of patients who have CKD and have undergone BITA or SITA grafting. This study's purpose was to determine whether BITA grafting is associated with reduced mortality for such patients. We retrospectively studied clinical outcomes of propensity score-matched and unmatched patients who had CKD and underwent 


\author{
Abbreviations and Acronyms \\ $\mathrm{BITA}=$ bilateral internal thoracic artery \\ $\mathrm{CKD}=$ chronic kidney disease \\ $\mathrm{CI}=$ confidence interval \\ GFR $=$ glomerular filtration rate \\ ITA $=$ internal thoracic artery \\ $\mathrm{OR}=$ odds ratio \\ SITA $=$ single internal thoracic artery
}

BITA or SITA grafting, to quantify any benefit of BITA grafting for this subset.

\section{METHODS}

Between January 2002 and June 2014, a total of 1284 consecutive patients underwent isolated coronary artery bypass grafting at our institution. Of this cohort, the data from 1203 patients were retrospectively analyzed after excluding those who: were transferred to our hospital after receiving percutaneous cardiopulmonary support $(n=6)$; or had only one target vessel in the left coronary area $(\mathrm{n}=75)$. Glomerular filtration rate (GFR) was estimated from the Modification of Diet in Renal Disease equation $^{3}$ :

GFR $\left(\mathrm{mL} /\right.$ minute $\left./ 1.73 \mathrm{~m}^{2}\right)=194 \times$ serum creatinine level $[\mathrm{mg} / \mathrm{dL}]^{-1.094} \times$ age [year] $^{-0.287} \times 0.739$ [if female].

Preoperative serum creatinine level was measured at admission. All patients had previously given consent for use of their medical records for research purposes. The study was approved by the institutional review board.

\section{Surgical Technique and Operative Data}

Details of the surgical techniques, including graft harvest, graft arrangement, and off-pump technique have been previously published. ${ }^{4,5}$ Briefly, during the study period, the internal thoracic artery (ITA) and right gastroepiploic artery were consistently skeletonized, using a harmonic scalpel, and used as an in situ graft. On rare occasions $(0.5 \% ; 7$ of 1284), when the right ITA was too short for grafting to the left anterior descending artery, or when the ITA was injured at its proximal portion, a composite graft was constructed with the free ITA anastomosed to the in situ ITA in an end-to-side fashion.

The left anterior descending artery was always revascularized using the ITA as an individual in situ graft. The second ITA and/or saphenous vein, as either a sequential or an individual graft, were grafted to the circumflex branches and/or the diagonal branches. The inferior wall was revascularized using the saphenous vein and/or the in-situ right gastroepiploic artery. The radial artery graft and endoscopic vein harvest were not used at all.

\section{Outcome Measures and Definitions}

The primary outcome measures were all-cause mortality and cardiacrelated mortality. Cardiac-related mortality included deaths caused by myocardial infarction or heart failure, and sudden death, defined as a sudden, unexpected pulseless condition, likely of cardiac origin. If unwitnessed, sudden cardiac deaths were those in which the patient was found dead, within 24 hours of having been seen alive and in an apparently normal state of health. Documentation of the cause of death was based on information obtained from witnesses, family members, death certificates, hospital records, and autopsy records.

The secondary measure was in-hospital outcomes and included 30-day mortality, stroke, and deep sternal infection. Stroke was defined as new focal neurologic symptoms lasting $>24$ hours, with radiographic evidence of infarction in the appropriate territory. Deep sternal infection was defined as any wound infection involving the sternum or mediastinal tissues that required operative intervention. Diabetes was defined as hemoglobin $A_{1 c}$ either $\geq 6.5 \%$ or currently being treated by a physician. End-stage renal disease was defined as GFR $<15 \mathrm{~mL} /$ minute $/ 1.73 \mathrm{~m}^{2}$, or being on dialysis. Hypertension was defined as currently being on pharmacologic therapy for hypertension, or documented blood pressure $>140 \mathrm{~mm} \mathrm{Hg}$ systolic, and/or $>90 \mathrm{~mm} \mathrm{Hg}$ diastolic, on $\geq 2$ separate occasions.

Peripheral arterial disease was defined as an ankle-brachial blood pressure index $<0.90$ in one or both legs. Cerebral vascular disease was defined as having a previous history of ischemic infarction of central nervous system tissue, either symptomatic or silent. This definition did not include nonvascular neurologic diseases or other acute neurologic insults, such as metabolic and anoxic ischemic encephalopathy. Heart failure was defined as persistent symptoms that limit daily life (New York Heart Association class III and IV) despite recommended therapies. All patient data were collected prospectively and entered in our database.

\section{Statistical Analysis}

Unadjusted differences between the SITA and BITA groups were compared, using $\chi^{2}$ analysis for categoric variables, and 2-tailed unpaired $t$ tests for continuous variables in the unmatched cohorts. McNemar tests and paired $t$ tests were used in the matched cohort.

Propensity-score matching was used to account for the nonequivalence of baseline characteristics between the BITA and SITA groups. A propensity score represents the predicted probability of a given patient being assigned to undergo BITA grafting. Propensity scores were calculated using a nonparsimonious multivariate logistic regression model, with BITA grafting as the dependent variable. All variables associated with graft selection based on clinical knowledge were entered into the model as covariates, to control for possible confounders (Table 1).

The propensity scores of patients who received BITA grafting (minimum: 0.098; maximum: 0.999) overlapped considerably with the scores of those who received SITA grafting (minimum: 0.045; maximum: 0.974). The area under the receiver operating characteristic curve was 0.82 (95\% confidence interval [CI]: 0.74-0.89, $P=.001)$, indicating strong differentiation between patients receiving a BITA versus a SITA graft. The Hosmer-Lemeshow goodness-of-fit $\chi^{2}$ for this model was $7.26(P=.509)$. One-to-one matching of SITA patients with BITA patients was conducted, using a nearest-neighbor matching algorithm without replacement, with a caliper width of $0.2 \mathrm{SD}$ of the logit of the propensity scores. Absolute standardized differences were calculated to compare balance in baseline characteristics between the BITA and SITA groups in the unmatched cohort with that in the matched cohort. ${ }^{6}$ An absolute standardized difference $>0.100$ was considered a meaningful imbalance.

To determine whether degrees of renal dysfunction influenced the prognostic significance of BITA grafting, survival analyses were performed in both unmatched and matched cohorts, stratified according to stages of CKD (GFR: $<30 ; 30-60 ;>60 \mathrm{~mL} /$ minute $/ 1.73 \mathrm{~m}^{2}$ ). The estimated survival rates were calculated using the Kaplan-Meier method and compared using the log-rank test. The hazard ratios and $95 \%$ CIs for the association between BITA grafting and all-cause mortality and cardiac-related mortality were estimated using Cox proportional hazard models in both unmatched and matched cohorts. In addition, a Cox model stratified on matched pairs was used to estimate the effect of BITA grafting on outcome.

Potential independent variables of outcomes were identified by bivariate analyses and entered in a stepwise manner into multivariable models of survival, with entry and retention set at a significance level of $P<.050$. The validity of the proportional hazard model assumption was assessed by plotting and visually inspecting negative $\log$ by negative $\log$ survival probabilities. No violation of the assumption was detected (Figure E1).

To identify risk factors associated with 30-day mortality, a multivariate logistic regression model with 30-day mortality as the dependent variable was developed using the unmatched cohort. BITA grafting, and variables that were associated with 30-day mortality based on clinical knowledge 
TABLE 1. Baseline characteristics in propensity-matched pairs

\begin{tabular}{|c|c|c|c|c|}
\hline Characteristic & $\begin{array}{l}\text { SITA } \\
\text { group }\end{array}$ & $\begin{array}{l}\text { BITA } \\
\text { group }\end{array}$ & $\begin{array}{c}P \\
\text { value }\end{array}$ & ASD \\
\hline No. patients & 412 & 412 & & \\
\hline Age (y) & $72 \pm 8$ & $72 \pm 8$ & .91 & 0.000 \\
\hline Age groups (y) & & & .72 & \\
\hline$<65$ & $98(24)$ & $104(25)$ & .63 & 0.034 \\
\hline $65-74$ & $140(34)$ & $138(33)$ & .88 & 0.010 \\
\hline$\geq 75$ & $174(42)$ & $170(41)$ & .78 & 0.020 \\
\hline Male & $322(78)$ & $332(81)$ & .39 & 0.060 \\
\hline Body mass index $\left(\mathrm{kg} / \mathrm{m}^{2}\right)$ & $23 \pm 2$ & $23 \pm 2$ & .98 & 0.000 \\
\hline Body surface area $\left(\mathrm{m}^{2}\right)$ & $1.6 \pm 0.2$ & $1.6 \pm 0.2$ & .98 & 0.000 \\
\hline Diabetes mellitus & $233(57)$ & $245(59)$ & .40 & 0.059 \\
\hline Hemoglobin $A_{1 c}(\%)$ & $6.2 \pm 1.1$ & $6.3 \pm 1.1$ & .32 & 0.091 \\
\hline$>7.5$ & $33(8)$ & $43(10)$ & .23 & 0.084 \\
\hline \multicolumn{5}{|l|}{ Diabetes therapy } \\
\hline Oral hypoglycemic agents & $79(19)$ & $92(22)$ & .26 & 0.072 \\
\hline Insulin & $56(14)$ & $65(16)$ & .38 & 0.031 \\
\hline GFR $\left(\mathrm{mL} / \mathrm{min} / 1.73 \mathrm{~m}^{2}\right)$ & $43 \pm 24$ & $45 \pm 22$ & .13 & 0.087 \\
\hline$>60$ & $73(18)$ & $83(20)$ & .65 & 0.062 \\
\hline $30-60$ & $221(54)$ & $223(54)$ & .89 & 0.010 \\
\hline$<30$ & $128(31)$ & $118(29)$ & .55 & 0.053 \\
\hline On dialysis & $51(12)$ & $45(11)$ & .52 & 0.045 \\
\hline Hypertension & $289(70)$ & $291(71)$ & .88 & 0.019 \\
\hline Obstructive pulmonary disease & $91(22)$ & $82(20)$ & .44 & 0.088 \\
\hline Peripheral arterial disease & $110(27)$ & $98(24)$ & .34 & 0.086 \\
\hline Cerebral vascular disease & $56(14)$ & $58(14)$ & .84 & 0.016 \\
\hline LV ejection fraction $<40 \%$ & $98(24)$ & $101(25)$ & .81 & 0.013 \\
\hline PCI history & $118(29)$ & $136(33)$ & .17 & 0.006 \\
\hline Myocardial infarction & $184(45)$ & $166(40)$ & .21 & 0.034 \\
\hline Heart failure & $165(40)$ & $148(36)$ & .22 & 0.075 \\
\hline NYHA class III or IV & $210(51)$ & $195(47)$ & .30 & 0.091 \\
\hline LV diastolic dimension (mm) & $52 \pm 10$ & $51 \pm 8$ & .09 & 0.110 \\
\hline LV systolic dimension (mm) & $37 \pm 10$ & $36 \pm 9$ & .33 & 0.105 \\
\hline LV ejection fraction $(\%)$ & $53 \pm 14$ & $52 \pm 14$ & .46 & 0.071 \\
\hline No. target coronary arteries & $3.4 \pm 1.1$ & $3.5 \pm 1.3$ & .15 & 0.077 \\
\hline
\end{tabular}

Values are $\mathrm{n}(\%)$, or mean $\pm \mathrm{SD}$, unless otherwise indicated. SITA, Single internal thoracic artery; BITA, bilateral internal thoracic artery; $A S D$, absolute standardized difference; GFR, glomerular filtration rate; $L V$, left ventricular; $P C I$, percutaneous coronary intervention; NYHA, New York Heart Association.

and had a significance level of $P<.050$ in univariate logistic regression models were entered into the multivariate model as covariates in a stepwise manner, with entry and retention set at a significance level of $P<.050$. The same analyses were performed with stroke and deep sternal infection as the dependent variable. Conditional logistic regression was used to determine the association between BITA grafting and in-hospital outcomes in the matched cohort.

Interaction between BITA grafting and estimated GFR was tested in both primary and secondary outcome models, with the use of interaction terms for BITA use and GFR. To examine multicollinearity of the models, we calculated the variance inflation factor for each variable in all multivariate models and confirmed that none was $>2$ (highest: 1.34), which indicates that multicollinearity was not a significant issue. All statistical testing was 2-sided. All analyses were performed with SPSS, version 20.0 (SPSS Inc, Chicago, Ill).

\section{RESULTS}

In the unmatched original cohort, patients who received BITA grafting were significantly younger, more often
TABLE 2. In-hospital outcomes in unmatched and matched cohorts

\begin{tabular}{lcccc}
\hline \multicolumn{1}{c}{ Cohort } & SITA group & BITA group & $\boldsymbol{P}$ value & ASD \\
\hline Unmatched & & & & \\
$\quad$ No. patients & 453 & 750 & & \\
Stroke & $9(2.0)$ & $8(1.1)$ & .19 & 0.075 \\
Deep sternal infection & $7(1.5)$ & $15(2.0)$ & .57 & 0.035 \\
30-d mortality & $8(1.8)$ & $7(0.9)$ & .21 & 0.072 \\
Matched & & & & \\
$\quad$ No. patients & 412 & 412 & & \\
Stroke & $8(1.9)$ & $3(0.7)$ & .22 & 0.106 \\
Deep sternal infection & $6(1.5)$ & $7(1.7)$ & .78 & 0.020 \\
30-d mortality & $6(1.5)$ & $4(1.0)$ & .75 & 0.044 \\
\hline
\end{tabular}

Values are $\mathrm{n}(\%)$, unless otherwise indicated. SITA, Single internal thoracic artery; BITA, bilateral internal thoracic artery; $A S D$, absolute standardized difference.

male, with greater body surface area, and a higher prevalence of both poorly controlled diabetes (hemoglobin $\mathrm{A}_{1 \mathrm{c}}$ level $>7.5 \%$ ) and peripheral arterial disease (Table E1). A total of 824 individuals $(54.9 \%$ of the BITA group; $91.0 \%$ of the SITA group) were matched according to propensity scores. After matching, no significant differences were found between the baseline characteristics of the 2 groups, and the absolute standardized differences were $<0.100$ for all matched variables, indicating an adequate match (Table 1).

\section{In-Hospital Outcomes}

Table 2 shows the in-hospital outcomes in unmatched and matched cohorts. In the unmatched cohort, the rate of 30day mortality and stroke tended to be higher in the SITA group, whereas the incidence of deep sternal infection was not significantly different in the 2 groups. The same tendency was observed in the matched cohort. As independent predictors for 30-day mortality, estimated GFR $<30 \mathrm{~mL} /$ minute $/ 1.73 \mathrm{~m}^{2}$ and heart failure were identified (Table E2). For deep sternal infection, high body mass index and hemoglobin $\mathrm{A}_{1 \mathrm{c}}$ level $>7.5 \%$ were found to be independent predictors (Table E3). Finally, manipulation of the ascending aorta, a hemoglobin $\mathrm{A}_{1 \mathrm{c}}$ level of $>7.5 \%$, and cerebral vascular disease, were significantly associated with a high risk of stroke (Table E4).

Conditional logistic regression models in the matched cohort did not change, but rather confirmed, the results, indicating that BITA grafting was not associated with risk of stroke (odds ratio [OR] $0.60,95 \%$ CI 0.21-1.71, $P=.55$ ); deep sternal infection (OR $1.32,95 \%$ CI 0.50 $3.48, P=.58$ ); and 30-day mortality (OR $0.68,95 \% \mathrm{CI}$ $0.26-1.78, P=.52$ ). Tests for interaction between BITA grafting and GFR in in-hospital outcome models were not significant.

\section{Remote Outcomes}

The follow-up rate of the patients was almost complete $(99.0 \%)$. The mean duration of the observation period in 


\section{A}

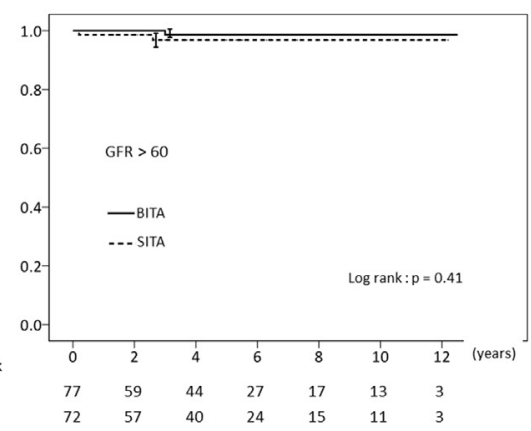

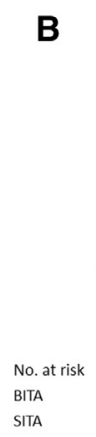

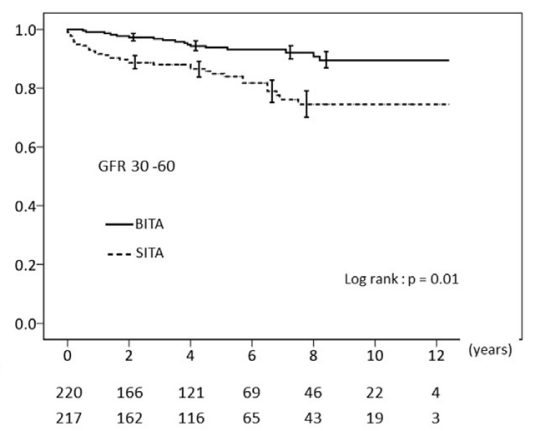

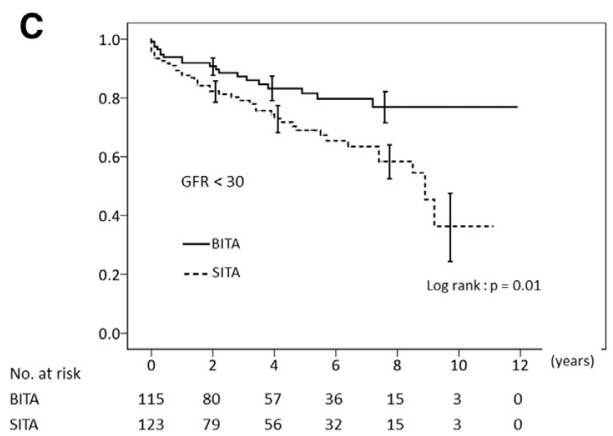

FIGURE 1. The figure shows survival, free from all-cause mortality in the matched cohort, stratified by chronic kidney disease stage: A, GFR, >60; (B) GFR, 30-60; (C) GFR, <30. (GFR given as: $\mathrm{mL} / \mathrm{minute} / 1.73 \mathrm{~m}^{2}$ ). Vertical bars indicate $68 \%$ confidence intervals (equivalent to $\pm 1 \mathrm{SE}$ ) of the KaplanMeier estimates. GFR, Glomerular filtration rate; BITA, bilateral internal thoracic artery; SITA, single internal thoracic artery.

the matched cohort was $5.6 \pm 3.3$ years in the BITA group, and $4.9 \pm 3.2$ years in the SITA group. Cardiac-related death occurred more often in the SITA group than in the BITA group (30 vs 11 , respectively, $P=.01$ ), but the incidence of noncardiac-related death was not significantly different (43 vs $28, P=.08$ ). The causes of death are listed in Table E5.

Estimated survival, free from all-cause and cardiac-related mortality, in the matched cohort, stratified by CKD stage, is shown in Figures 1 and 2 (respective rates in the unmatched cohort are shown in Figures E2 and E3). Patients with normal renal function had excellent survival, regardless of whether
BITA was used. Although an advanced stage of CKD decreased overall survival, a benefit of BITA grafting occurred relatively early in the follow-up period and was not influenced by the stage of CKD. Multivariate Cox proportional hazard models including patients with GFR $<60 \mathrm{~mL} /$ minute $/ 1.73 \mathrm{~m}^{2}$ showed that BITA grafting was independently associated with a lower risk of both allcause and cardiac-related mortality in both unmatched (Table E6) and matched cohorts (Table 3). Tests for interaction between BITA grafting and GFR were not significant in either model, indicating a lack of association of BITA grafting and GFR with primary outcomes.
A

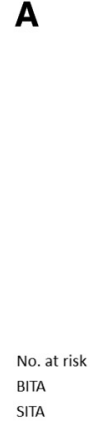

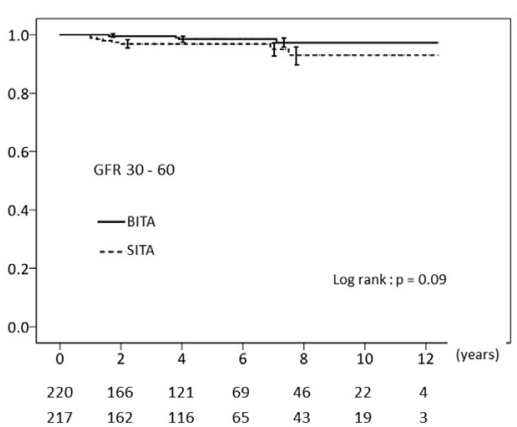
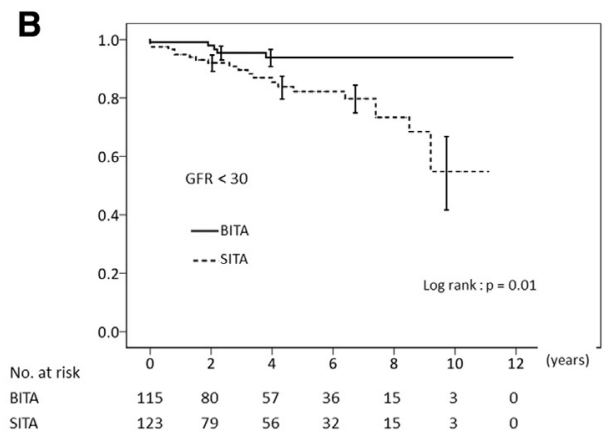

FIGURE 2. The figure shows survival, free from cardiac-related mortality, in the matched cohort, stratified by chronic kidney disease stage: A, GFR, 30-60; (B) GFR, $<30$. (GFR given as: $\mathrm{mL} /$ minute $/ 1.73 \mathrm{~m}^{2}$ ). No survival curves are shown for patients with GFR $>60 \mathrm{~mL} / \mathrm{min} / 1.73 \mathrm{~m}^{2}$ because no patients in this group died. Vertical bars indicate $68 \%$ confidence intervals (equivalent to \pm 1 SE) of the Kaplan-Meier estimates. GFR, Glomerular filtration rate; BITA, bilateral internal thoracic artery; SITA, single internal thoracic artery. 
TABLE 3. Multivariate Cox proportional hazard models for the association of patient factors with all-cause and cardiac-related mortality in matched patients with GFR $<60 \mathrm{~mL} / \mathrm{min} / 1.73 \mathrm{~m}^{2}$

\begin{tabular}{lccc}
\hline \multicolumn{1}{c}{ Factor } & HR & $\mathbf{9 5} \% \mathbf{C I}$ & $\boldsymbol{P}$ value \\
\hline All-cause mortality & & & \\
BITA grafting & 0.57 & $0.38-0.86$ & .01 \\
Age per 1-SD increase & 1.40 & $1.12-1.75$ & .01 \\
Body mass index per 1-SD increase & 0.79 & $0.67-0.93$ & .01 \\
End-stage renal failure & 3.02 & $1.97-4.63$ & .01 \\
Peripheral arterial disease & 1.90 & $1.26-2.87$ & .01 \\
Prior myocardial infarction & 1.93 & $1.31-2.84$ & .01 \\
BITA grafting* GFR & & & .45 \\
Cardiac-related mortality & & & \\
BITA grafting & 0.41 & $0.21-0.84$ & .01 \\
End-stage renal failure & 8.08 & $4.23-15.43$ & .01 \\
Peripheral arterial disease & 2.71 & $1.43-5.14$ & .01 \\
Prior myocardial infarction & 2.99 & $1.57-5.69$ & .01 \\
Heart failure & 1.95 & $1.04-3.66$ & .04 \\
BITA grafting* GFR & & & .25 \\
\hline
\end{tabular}

$H R$, Hazard ratio; $C I$, confidence interval; $S D$, standard deviation; BITA, bilateral internal thoracic artery; GFR, glomerular filtration rate. *Indicates interaction term for BITA grafting and GFR which is included in multivariate models.

\section{DISCUSSION}

One major finding of this study is that revascularization using skeletonized BITAs as in situ grafts to the left coronary area was independently associated with a lower risk of both all-cause and cardiac-related mortality, without worsening in-hospital outcomes in patients who have CKD. The other major finding is that this survival benefit was not influenced by the stage of CKD.

Many researchers have shown that the surgical strategy of BITA grafting incrementally improves long-term survival. $^{7-12}$ Despite these data, BITA grafting has not been widely adopted. One reason is the common belief that the survival benefit of BITA grafting becomes apparent only after a decade of follow-up. The divergence of survival curves in the early postoperative period in the present study distinguishes it from previous, larger studies of survival after BITA versus SITA grafting, in which the curves diverged only after much longer periods of time, sometimes 7 to 10 years.

Our finding does, however, concur with the results reported by the Cleveland Clinic group who compared outcomes in 1152 propensity score-matched pairs receiving BITA or SITA grafting. ${ }^{11}$ They demonstrated that risk factors such as advanced age, abnormal left ventricular function, diabetes, and peripheral arterial disease reduced overall survival, but that the incremental benefit of BITA grafting became clear soon after surgery and persisted during follow-up in such high-risk patients. A few recent reports also have shown better outcomes with BITA grafting at early follow-up in high-risk patient groups. ${ }^{5,13-15}$

One feasible explanation for this phenomenon is that the ITA is more likely to be patent than the saphenous vein, when grafted to the left coronary area, at all times after surgery. ${ }^{16}$ Early vein graft failure has been reported in recent publications. In the PREVENT IV multicenter randomized trial, in which 3014 patients undergoing isolated coronary artery bypass were enrolled, the incidence of vein graft failure at 12 months was significantly higher than that of ITA graft failure (25\% vs $8 \%){ }^{17}$ The ROOBY (Randomized On/Off Bypass) trial similarly demonstrated that a vein graft failed more frequently than an ITA graft early after surgery, both on and off pump. ${ }^{18}$

Vein graft failure does not always cause a negative outcome. However, a small myocardial infarction caused by early vein graft failure, which is clinically unimportant to young, low-risk patients, may result in clinically important consequences in elderly, high-risk patients. This fact may explain the survival curve in the SITA group, which declined dramatically in the early phase. Patients enrolled in the present study who had CKD were significantly older and more likely to have risk factors such as diabetes, hypertension, peripheral arterial disease, cerebral vascular disease, and heart failure (Table E4). We believe that the higher risks faced by these patients may explain the difference in survival timelines. Controversy remains in the real world of cardiac surgery, but to make progress, we may need to change our mindsets toward coronary artery bypass surgery.

The method of using the right internal thoracic artery for BITA grafting remains a key issue. ${ }^{19-21}$ We skeletonized almost exclusively the right internal thoracic artery, routed anterior to the ascending aorta across the midline, and anastomosed to the distal left anterior descending artery, in an in situ, individual graft fashion. We chose this approach because right internal thoracic artery grafting to the right coronary artery has been shown to fail more frequently than grafting to the left coronary areas, ${ }^{16}$ and decreased midterm survival and reduced patency of composite grafts have been reported. ${ }^{22,23}$ Some surgeons may not consent to bringing the right internal thoracic artery in front of the heart, for fear of increased danger in future re-sternotomy, and the complexity of a redo operation. In addition, without the tedious skeletonization of the whole length of the right internal thoracic artery, it becomes shorter and can reach target sites with only the thin and spastic, distal part of the artery.

Deep sternal infection is one of the major concerns with BITA grafting. The incidence and risk factors for such infection in this study are roughly in accordance with those in previous studies. ${ }^{13,24,25}$ No significant difference was observed between the 2 groups in the incidence of deep sternal infection. Although some surgeons might say that this is a type II error, the standardized difference, which is less susceptible to sample size, was 0.054 in the unmatched cohort, and 0.044 in the matched cohort, indicating little difference between the 2 groups.

The skeletonization technique might contribute to reduction of this complication. ${ }^{26}$ We are aware that BITA use 
tends to be associated with an increased risk for deep sternal infection because harvesting of both ITAs theoretically reduces blood supply to the sternum much more than that of a single ITA, even when skeletonization is properly applied. But we believe that the survival benefit patients receive from BITA grafting outweighs the potential risk of deep sternal infection.

Finding a way to minimize the risk of postoperative stroke is an important mission for cardiac surgeons, because it is the only major complication for which percutaneous coronary intervention has been demonstrated to be more advantageous compared with coronary artery bypass surgery. ${ }^{27}$ In the present study, stroke occurred more often in the SITA group, but this result may be attributed to the fact that the SITA group underwent much more aortic manipulation (vein-to-aorta proximal anastomosis) than the BITA group did. As evidenced by several studies, ${ }^{28-30}$ manipulation of the ascending aorta has been proposed as the leading cause of cerebral embolism, and the true benefit of offpump coronary artery bypass grafting can be seen only when aortic manipulation is completely avoided.

Grafting strategy is one of the few factors that can be left to the discretion of surgeons. Our choices of conduits other than ITA were the saphenous vein or right gastroepiploic artery. For prevention of postoperative stroke, an in situ grafting of the right gastroepiploic artery may be better than grafting of the saphenous vein, although use of the right gastroepiploic artery requires careful consideration of the degree of target coronary stenosis. ${ }^{31}$

The present study has several limitations. First, even with propensity matching, a completely fair comparison between BITA and SITA grafting could not be performed. Although the propensity score can adjust for confounding by indication and selection bias, residual unobserved confounding cannot be eliminated. Second, all enrolled subjects were Japanese patients at a single center, which limits generalizability of the findings. Finally, the lack of available coronary angiographic data did not allow us to evaluate whether the survival benefit of BITA grafting is related to graft patency.

To summarize, off-pump, skeletonized, left-side BITA grafting is independently associated with a lower risk of all-cause and cardiac-related mortality in patients who have CKD. Additionally, this type of grafting does not increase the incidence of stroke or deep sternal infection in these patients.

\section{Conflict of Interest Statement}

Authors have nothing to disclose with regard to commercial support.

\section{References}

1. Hillis GS, Croal BL, Buchan KG, El-Shafei H, Gibson G, Jeffrey RR, et al. Renal function and outcome from coronary artery bypass grafting: impact on mortality after a 2.3-year follow-up. Circulation. 2006;113:1056-62.
2. Cooper WA, O'Brien SM, Thourani VH, Guyton RA, Bridges CR, Szczech LA, et al. Impact of renal dysfunction on outcomes of coronary artery bypass surgery: results from the Society of Thoracic Surgeons National Adult Cardiac Database. Circulation. 2006;113:1063-70.

3. Matsuo S, Imai E, Horio M, Yasuda Y, Tomita K, Nitta K, et al. Revised equations for estimated GFR from serum creatinine in Japan. Am J Kidney Dis. 2009;53: 982-92.

4. Asai T, Suzuki T, Nota H, Kuroyanagi S, Kinoshita T, Takashima N, et al. Offpump coronary artery bypass grafting using skeletonized in situ arterial grafts. Ann Cardiothorac Surg. 2013;2:552-6.

5. Kinoshita T, Asai T, Suzuki T, Kambara A, Matsubayashi K. Off-pump bilateral versus single skeletonized internal thoracic artery grafting in high-risk patients. Circulation. 2011;124(11 Suppl):S130-4.

6. Austin PC. Balance diagnostics for comparing the distribution of baseline covariates between treatment groups in propensity-score matched samples. Stat Med. 2009;28:3083-107.

7. Dorman MJ, Kurlansky PA, Traad EA, Galbut DL, Zucker M, Ebra G. Bilateral internal mammary artery grafting enhances survival in diabetic patients: a 30year follow-up of propensity score-matched cohorts. Circulation. 2012;126: 2935-42.

8. Benedetto U, Amrani M, Raja SG. Harefield Cardiac Outcomes Research Group. Guidance for the use of bilateral internal thoracic arteries according to survival benefit across age groups. J Thorac Cardiovasc Surg. 2014;148:2706-11.

9. Buxton BF, Shi WY, Tatoulis J, Fuller JA, Rosalion A, Hayward PA. Total arterial revascularization with internal thoracic and radial artery grafts in triple-vessel coronary artery disease is associated with improved survival. J Thorac Cardiovasc Surg. 2014;148:1238-43.

10. Takagi H, Goto SN, Watanabe T, Mizuno Y, Kawai N, Umemoto T. A metaanalysis of adjusted hazard ratios from 20 observational studies of bilateral versus single internal thoracic artery coronary artery bypass grafting. $J$ Thorac Cardiovasc Surg. 2014;148:1282-90.

11. Lytle BW, Blackstone EH, Sabik JF, Houghtaling P, Loop FD, Cosgrove DM. The effect of bilateral internal thoracic artery grafting on survival during 20 postoperative years. Ann Thorac Surg. 2004;78:2005-12.

12. Taggart DP, D'Amico R, Altman DG. Effect of arterial revascularisation on survival: a systematic review of studies comparing bilateral and single internal mammary arteries. Lancet. 2001;358:870-5.

13. Puskas JD, Sadiq A, Vassiliades TA, Kilgo PD, Lattouf OM. Bilateral internal thoracic artery grafting is associated with significantly improved long-term survival, even among diabetic patients. Ann Thorac Surg. 2012;94:710-5.

14. Kinoshita T, Asai T, Suzuki T, Kuroyanagi S, Hosoba S, Takashima N. Off-pump bilateral skeletonized internal thoracic artery grafting in elderly patients. Ann Thorac Surg. 2012;93:531-6.

15. Benedetto U, Montecalvo A, Kattach H, Amrani M, Raja SG, Harefield Cardiac Outcomes Research Group. Impact of the second internal thoracic artery on short- and long-term outcomes in obese patients: a propensity score matched analysis. J Thorac Cardiovasc Surg. 2014;149:841-7.

16. Sabik JF, Lytle BW, Blackstone EH, Houghtaling PL, Cosgrove DM. Comparison of saphenous vein and internal thoracic artery graft patency by coronary system. Ann Thorac Surg. 2005;79:544-51.

17. Magee MJ, Alexander JH, Hafley G, Ferguson TB Jr, Gibson CM, Harrington RA, et al. On-pump and off-pump coronary artery bypass: findings from PREVENT IV. Ann Thorac Surg. 2008;85:494-500.

18. Shroyer AL, Grover FL, Hattler B, Collins JF, McDonald GO, Kozora E, et al. On-pump and off-pump coronary-artery bypass surgery. N Engl J Med. 2009; 361:1827-37.

19. Tranbaugh RF, Dimitrova KR, Lucido DJ, Hoffman DM, Dincheva GR, Geller CM, et al. The second best arterial graft: a propensity analysis of the radial artery versus the free right internal thoracic artery to bypass the circumflex coronary artery. J Thorac Cardiovasc Surg. 2014;147:133-40.

20. Raja SG, Benedetto U, Husain M, Soliman R, De Robertis F, Amrani M, et al. Does grafting of the left anterior descending artery with the in situ right internal thoracic artery have an impact on late outcomes in the context of bilateral internal thoracic artery usage? J Thorac Cardiovasc Surg. 2014;148:1275-81.

21. Kim KB, Hwang HY, Hahn S, Kim JS, Oh SJ. A randomized comparison of the Saphenous Vein Versus Right Internal Thoracic Artery As a Y-Composite Graft (SAVE RITA) trial: one-year angiographic results and mid-term clinical outcomes. J Thorac Cardiovasc Surg. 2014;148:901-7.

22. Pevni D, Hertz I, Medalion B, Kramer A, Paz Y, Uretzky G, et al. Angiographic evidence for reduced graft patency due to competitive flow in composite arterial T-grafts. J Thorac Cardiovasc Surg. 2007;133:1220-5. 
23. Manabe S, Fukui T, Shimokawa T, Tabata M, Katayama Y, Morita S, et al. Increased graft occlusion or string sign in composite arterial grafting for mildly stenosed target vessels. Ann Thorac Surg. 2010;89:683-8.

24. Hemo E, Mohr R, Uretzky G, Katz G, Popovits N, Pevni D, et al. Long-term outcomes of patients with diabetes receiving bilateral internal thoracic artery grafts. J Thorac Cardiovasc Surg. 2013;146:586-92.

25. Kieser TM, Rose MS, Aluthman U, Montgomery M, Louie T, Belenkie I. Toward zero: deep sternal wound infection after 1001 consecutive coronary artery bypass procedures using arterial grafts: implications for diabetic patients. J Thorac Cardiovasc Surg. 2014;148:1887-95.

26. Saso S, James D, Vecht JA. Effect of skeletonization of the internal thoracic artery for coronary revascularization on the incidence of sternal wound infection. Ann Thorac Surg. 2010;89:661-70.

27. Serruys PW, Morice MC, Kappetein AP, Colombo A, Holmes DR, Mack MJ, et al. Percutaneous coronary intervention versus coronary-artery bypass grafting for severe coronary artery disease. N Engl J Med. 2009;360:961-72.
28. Kapetanakis EI, Stamou SC, Dullum MK, Hill PC, Haile E, Boyce SW, et al. The impact of aortic manipulation on neurologic outcomes after coronary artery bypass surgery: a risk-adjusted study. Ann Thorac Surg. 2004;78:1564-71.

29. Lev-Ran O, Braunstein R, Sharony R, Kramer A, Paz Y, Mohr R, et al. No-touch aorta off-pump coronary surgery: the effect on stroke. J Thorac Cardiovasc Surg. 2005; 129:307-13.

30. Moss E, Puskas JD, Thourani VH, Kilgo P, Chen EP, Leshnower BG, et al. Avoid ing aortic clamping during coronary artery bypass grafting reduces postoperative stroke. J Thorac Cardiovasc Surg. 2015;149:175-80.

31. Suzuki T, Asai T, Nota H, Kuroyanagi S, Kinoshita T, Takashima N, et al. Early and long-term patency of in situ skeletonized gastroepiploic artery after off-pump coronary artery bypass graft surgery. Ann Thorac Surg. 2013;96:90-5.

Key Words: arterial graft, coronary artery bypass graft, chronic kidney disease, off-pump surgery, propensity score

\title{
EDITORIAL COMMENTARY
}

\section{Spending 30 minutes to add years to a patient's life: Why is the last step so difficult?}

\author{
Antonio Maria Calafiore, MD, ${ }^{\mathrm{a}}$ Angela Lorena Iacò, MD, ${ }^{\mathrm{a}}$ and Michele Di Mauro, $\mathrm{MD}^{\mathrm{b}}$
}

See related article on pages 315-21.

In this issue of the Journal, Kinoshita and colleagues ${ }^{1}$ report the long-term outcomes of patients with chronic kidney disease who underwent coronary artery bypass grafting with skeletonized single internal thoracic artery (ITA) or bilateral ITA (BITA) grafts. After propensity matching, BITA grafting was associated with lower risks of allcause and cardiac-related mortalities, without any increase in early mortality or morbidity. This study is another "brick in the wall" in favor of the use of BITA in routine myocardial revascularization. There are many studies reporting increased long-term survival in high-risk patients when BITA grafting is compared with single ITA grafting. Obese, ${ }^{2}$ diabetic, ${ }^{3-5}$ high-risk (log EuroScore I, $\geq 5$ ) ${ }^{6}$ and

\footnotetext{
From the ${ }^{\text {a} D e p a r t m e n t ~ o f ~ A d u l t ~ C a r d i a c ~ S u r g e r y, ~ P r i n c e ~ S u l t a n ~ C a r d i a c ~ C e n t e r, ~}$ Riyadh, Saudi Arabia; and the ${ }^{\mathrm{b}}$ Department of Cardiovascular Disease, University of L'Aquila, L'Aquila, Italy.

Disclosures: Authors have nothing to disclose with regard to commercial support.

Received for publication May 3, 2015; accepted for publication May 5, 2015; available ahead of print June 20, 2015.

Address for reprints: Antonio Maria Calafiore, MD, Director, Department of Research, Consultant, Department of Adult Cardiac Center, Prince Sultan Cardiac Center, Riyadh, Kingdom of Saudi Arabia (E-mail: am.calafiore@gmail.com). J Thorac Cardiovasc Surg 2015;150:321-2 $0022-5223 / \$ 36.00$

Copyright (C) 2015 by The American Association for Thoracic Surgery http://dx.doi.org/10.1016/j.jtcvs.2015.05.018
}

elderly ${ }^{7}$ patients, even with reduced ejection fraction, ${ }^{8}$ all have the benefit of a longer survival when BITA grafting is used. Now Kinoshita and colleagues ${ }^{1}$ have nicely demonstrated that BITA grafting provides survival advantage even to patients with significant renal impairment.

Nowadays, there is over-

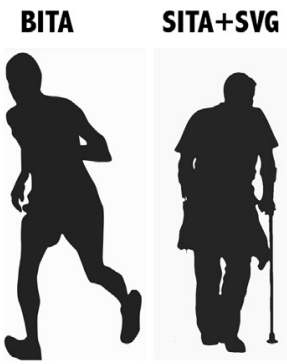
whelming evidence that BITA grafting is by far superior to single ITA grafting. Nevertheless, a recent analysis of the Society of Thoracic Surgeons database showed that use of BITA was 3.5\% in 1999 and 4.1\% in 2009. . Why then are surgeons reluctant to use it routinely?

Lack of specific competence is the first reason. Most surgeons do not know the proper way to use the right ITA; they are not expert on how to deal with T-grafting, Y-grafting, and sequential grafting. They are afraid to use the right ITA over the aorta to reach the LAD or under the aorta to reach the lateral wall. Providing the patients a "standard of care" treatment (left ITA and saphenous vein grafts) removes any technical issue and protects them from any legal complaint in case of complications. Randomized trials are lacking (the Arterial Revascularisation Trial $^{10}$ is still ongoing). Propensity matching, however, allows us to include more patients and to provide results more similar to those obtained in the real world. We cannot ignore 


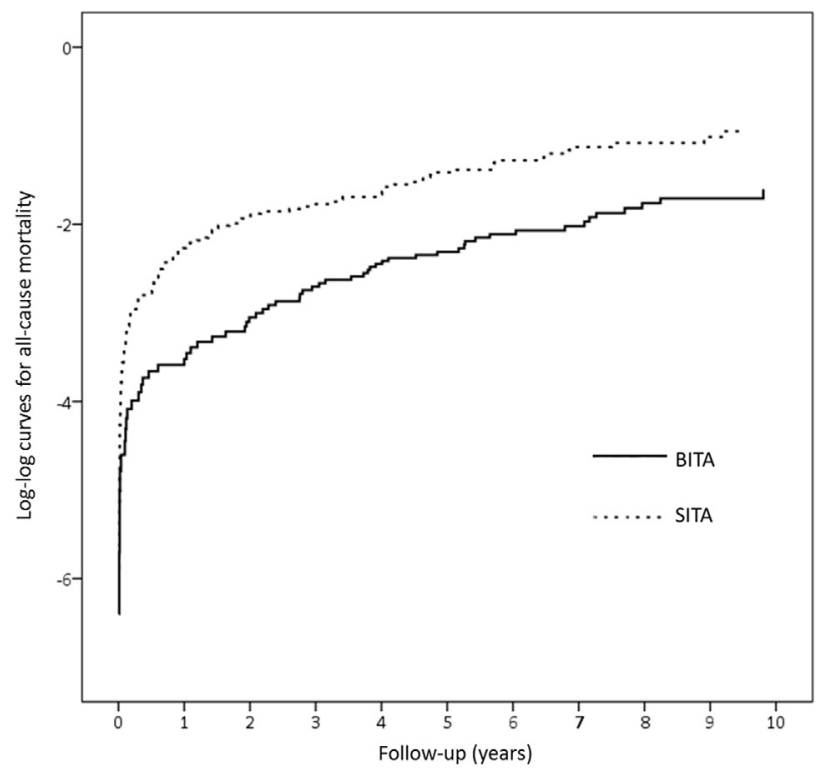

FIGURE E1. Proportional hazard model assumption was assessed by plotting and visually inspecting negative log by negative log survival probabilities. No violation of the assumption was detected. BITA, Bilateral internal thoracic artery; SITA, single internal thoracic artery.
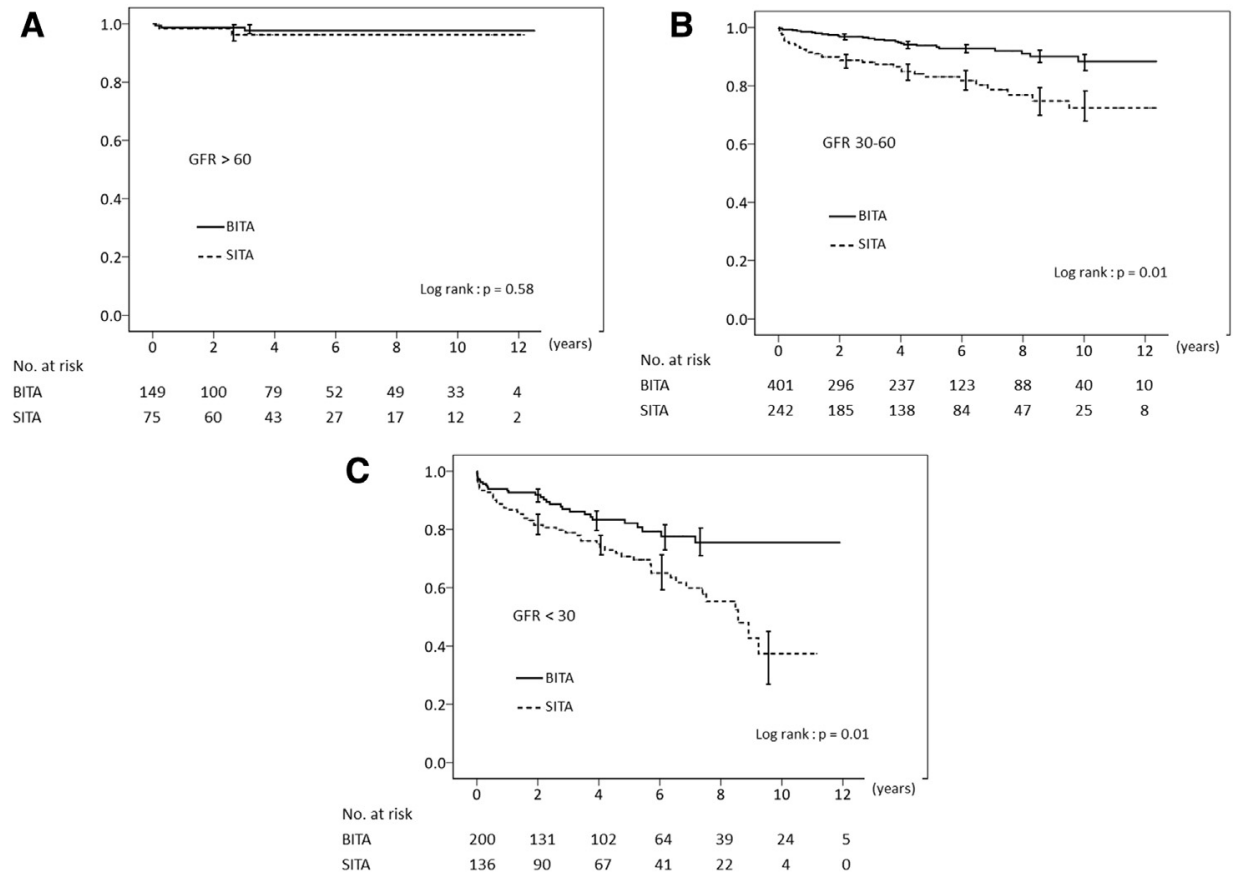

FIGURE E2. The figure shows survival, free from all-cause mortality, in the unmatched cohort, stratified by CKD stage: A, GFR, >60; (B) GFR, 30-60; (C) GFR, $<30$. (GFR given as: $\mathrm{mL} /$ minute $/ 1.73 \mathrm{~m}^{2}$ ). Vertical bars indicate $68 \%$ confidence intervals (equivalent to $\pm 1 \mathrm{SE}$ ) of the Kaplan-Meier estimates. GFR, Glomerular filtration rate; BITA, bilateral internal thoracic artery; SITA, single internal thoracic artery. 
A

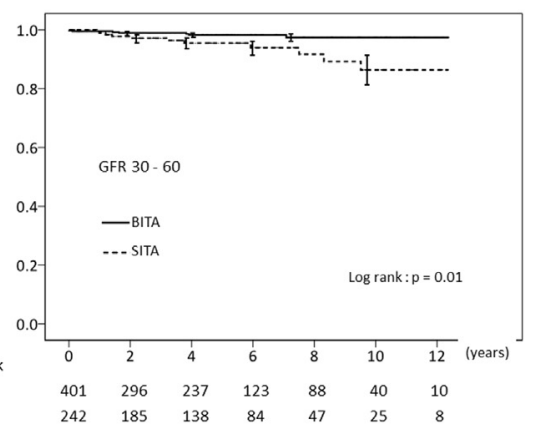

B

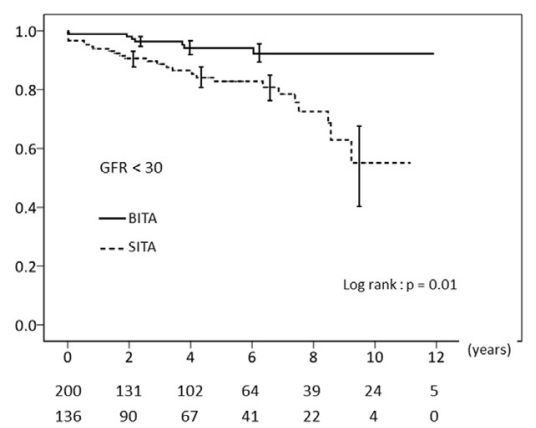

FIGURE E3. The figure shows survival, free from cardiac-related mortality, in the unmatched cohort, stratified by CKD stage: A, GFR, 30-60; (B) GFR, $<30$. (GFR given as: $\mathrm{mL} / \mathrm{minute} / 1.73 \mathrm{~m}^{2}$ ). No survival curves are shown for patients with GFR $>60 \mathrm{~mL} / \mathrm{min} / 1.73 \mathrm{~m}^{2}$ because no patients in this group died. Vertical bars indicate $68 \%$ confidence intervals (equivalent to $\pm 1 \mathrm{SE}$ ) of the Kaplan-Meier estimates. GFR, Glomerular filtration rate; BITA, bilateral internal thoracic artery; SITA, single internal thoracic artery.

TABLE E1. Baseline characteristics in original unmatched cohort

\begin{tabular}{|c|c|c|c|c|}
\hline Characteristics & $\begin{array}{l}\text { SITA } \\
\text { group }\end{array}$ & $\begin{array}{l}\text { BITA } \\
\text { group }\end{array}$ & $\begin{array}{c}P \\
\text { value }\end{array}$ & ASD \\
\hline No. patients & 453 & 750 & & \\
\hline Age (y) & $71 \pm 9$ & $69 \pm 8$ & .01 & 0.250 \\
\hline Age group (y) & & & .01 & \\
\hline$<65$ & $112(25)$ & $210(28)$ & & 0.074 \\
\hline $65-74$ & $153(34)$ & $287(38)$ & & 0.094 \\
\hline$\geq 75$ & $188(42)$ & $253(34)$ & & 0.161 \\
\hline Male & $344(76)$ & $628(84)$ & .01 & 0.195 \\
\hline Body mass index $\left(\mathrm{kg} / \mathrm{m}^{2}\right)$ & $22.8 \pm 3.3$ & $23.3 \pm 3.2$ & .01 & 0.154 \\
\hline Body surface area $\left(\mathrm{m}^{2}\right)$ & $1.62 \pm 0.18$ & $1.67 \pm 0.18$ & .01 & 0.278 \\
\hline Diabetes mellitus & $248(55)$ & $460(61)$ & .02 & 0.134 \\
\hline Hemoglobin $\mathrm{A}_{1 \mathrm{c}}(\%)$ & $6.2 \pm 1.0$ & $6.4 \pm 1.1$ & .04 & 0.190 \\
\hline$>7.5$ & $43(9)$ & $120(16)$ & .01 & 0.196 \\
\hline Diabetes therapy & & & .19 & \\
\hline Oral hypoglycemic agents & $88(19)$ & $170(23)$ & & 0.080 \\
\hline Insulin & $63(14)$ & $116(15)$ & & 0.044 \\
\hline GFR $\left(\mathrm{mL} / \mathrm{min} / 1.73 \mathrm{~m}^{2}\right)$ & $42 \pm 22$ & $46 \pm 20$ & .01 & 0.190 \\
\hline$>60$ & $75(17)$ & $149(20)$ & .15 & 0.086 \\
\hline $30-60$ & $242(53)$ & $401(53)$ & .99 & 0.001 \\
\hline$<30$ & $136(30)$ & $200(27)$ & .21 & 0.075 \\
\hline On dialysis & $55(12)$ & $74(10)$ & .22 & 0.075 \\
\hline Hypertension & $303(67)$ & $523(70)$ & .30 & 0.061 \\
\hline $\begin{array}{l}\text { Obstructive pulmonary } \\
\text { disease }\end{array}$ & $101(22)$ & $144(19)$ & .20 & 0.076 \\
\hline Peripheral arterial disease & $111(25)$ & $132(18)$ & .00 & 0.170 \\
\hline Cerebral vascular disease & $65(14)$ & $102(14)$ & .72 & 0.022 \\
\hline LV ejection fraction $<40 \%$ & $102(23)$ & $172(23)$ & .87 & 0.010 \\
\hline PCI history & $132(29)$ & $255(34)$ & .08 & 0.105 \\
\hline Myocardial infarction & $198(44)$ & $302(40)$ & .24 & 0.070 \\
\hline Heart failure & $180(40)$ & $259(35)$ & .07 & 0.108 \\
\hline NYHA class III or IV & $231(51)$ & $371(49)$ & .61 & 0.031 \\
\hline $\mathrm{LV}$ diastolic dimension $(\mathrm{mm})$ & $52 \pm 8$ & $51 \pm 7$ & .04 & 0.133 \\
\hline LV systolic dimension (mm) & $37 \pm 9$ & $36 \pm 8$ & .27 & 0.117 \\
\hline LV ejection fraction $(\%)$ & $53 \pm 14$ & $52 \pm 14$ & .33 & 0.071 \\
\hline No. target coronary arteries & $3.3 \pm 1.1$ & $3.5 \pm 1.1$ & .09 & 0.182 \\
\hline
\end{tabular}

TABLE E2. Univariate and multivariate logistic regression analyses for the association of patient factors with 30-day mortality in the unmatched cohort

\begin{tabular}{|c|c|c|c|c|c|c|}
\hline \multirow[b]{2}{*}{ Factor } & \multicolumn{3}{|c|}{ Univariate } & \multicolumn{3}{|c|}{ Multivariate } \\
\hline & OR & $95 \% \mathrm{CI}$ & $\begin{array}{c}P \\
\text { value }\end{array}$ & OR & $95 \%$ CI & $\begin{array}{c}P \\
\text { value }\end{array}$ \\
\hline BITA grafting & 0.52 & $0.19-1.46$ & .21 & & & \\
\hline Age per 1-SD increase & 1.33 & $0.88-2.01$ & .12 & & & \\
\hline BMI per 1-SD increase & 0.42 & $0.28-0.63$ & .01 & 0.62 & $0.32-1.20$ & .15 \\
\hline Male & 1.21 & $0.41-3.55$ & .73 & & & \\
\hline Diabetes mellitus & 2.01 & $0.83-4.85$ & .11 & & & \\
\hline $\begin{array}{l}\text { Hemoglobin } A_{1 c}>7.5 \% \\
\text { GFR }\left(\mathrm{mL} / \mathrm{min} / 1.73 \mathrm{~m}^{2}\right)\end{array}$ & 1.03 & $0.20-4.82$ & .87 & & & \\
\hline$>60$ & 1 & & & 1 & & \\
\hline $30-60$ & 2.10 & $0.53-8.32$ & .49 & 2.33 & $0.65-8.35$ & .44 \\
\hline$<30$ & 5.56 & $1.92-16.10$ & .01 & 6.10 & $1.88-19.79$ & .03 \\
\hline Hypertension & 0.57 & $0.26-1.27$ & .17 & & & \\
\hline $\begin{array}{l}\text { Peripheral arterial } \\
\text { disease }\end{array}$ & 2.11 & $0.90-4.96$ & .08 & & & \\
\hline $\begin{array}{l}\text { Cerebral vascular } \\
\text { disease }\end{array}$ & 0.90 & $0.27-3.05$ & .87 & & & \\
\hline $\begin{array}{l}\text { LV ejection fraction } \\
\quad<40 \%\end{array}$ & 1.25 & $0.52-3.03$ & .62 & & & \\
\hline $\begin{array}{l}\text { Prior myocardial } \\
\text { infarction }\end{array}$ & 2.79 & $1.24-6.26$ & .01 & 2.43 & $0.88-6.71$ & .09 \\
\hline Heart failure & 5.48 & $2.16-13.92$ & .01 & 4.07 & $1.57-10.56$ & .01 \\
\hline LMT $>50 \%$ stenosis & 1.68 & $0.76-3.70$ & .20 & & & \\
\hline OT per 1-SD increase & 1.08 & $0.72-1.62$ & .60 & & & \\
\hline BITA grafting* GFR & & & & & & .23 \\
\hline
\end{tabular}

$O R$, Odds ratio; $C I$, confidence interval; $B I T A$, bilateral internal thoracic artery; $S D$, standard deviation; $B M I$, body mass index; GFR, glomerular filtration rate; $L V$, left ventricular; $L M T$, left main trunk; $O T$, operation time. *Indicates interaction term for BITA grafting and GFR which is included in multivariate models. 
TABLE E3. Univariate and multivariate logistic regression analyses for the association of patient factors with deep sternal infection in the unmatched cohort

\begin{tabular}{|c|c|c|c|c|c|c|}
\hline \multirow[b]{2}{*}{ Factor } & \multicolumn{3}{|c|}{ Univariate } & \multicolumn{3}{|c|}{ Multivariate } \\
\hline & OR & $95 \% \mathrm{CI}$ & $\begin{array}{c}P \\
\text { value }\end{array}$ & OR & $95 \%$ CI & $\begin{array}{c}P \\
\text { value }\end{array}$ \\
\hline BITA grafting & 1.30 & $0.53-3.32$ & .57 & & & \\
\hline Age per 1-SD increase & 0.75 & $0.55-1.02$ & .06 & & & \\
\hline BMI per $1-S D$ increase & 1.77 & $1.29-2.44$ & .01 & 1.92 & $1.33-2.77$ & .01 \\
\hline Male & 1.86 & $0.65-5.32$ & .24 & & & \\
\hline Hemoglobin $\mathrm{A}_{1 \mathrm{c}}>7.5 \%$ & 2.77 & $1.25-6.14$ & .01 & 2.17 & $1.41-3.34$ & .01 \\
\hline \multicolumn{7}{|l|}{ GFR } \\
\hline$>60$ & 1 & & & & & \\
\hline $30-60$ & 1.23 & $0.57-2.65$ & .68 & & & \\
\hline$<30$ & 1.98 & $0.68-5.77$ & .42 & & & \\
\hline Hypertension & 0.80 & $0.40-1.60$ & .53 & & & \\
\hline Peripheral arterial disease & 1.27 & $0.57-2.82$ & .59 & & & \\
\hline Cerebral vascular disease & 1.34 & $0.55-3.27$ & .52 & & & \\
\hline LV ejection fraction $<40 \%$ & 1.42 & $0.69-2.93$ & .33 & & & \\
\hline Prior myocardial infarction & 0.60 & $0.28-1.28$ & .18 & & & \\
\hline Heart failure & 1.43 & $0.73-2.79$ & .29 & & & \\
\hline OT per 1-SD increase & 1.20 & $0.89-1.62$ & .10 & & & \\
\hline Perioperative transfusion & 1.08 & $0.56-2.10$ & .82 & & & \\
\hline BITA grafting* GFR & & & & & & .10 \\
\hline
\end{tabular}

TABLE E4. Univariate and multivariate logistic regression analyses for the association of patient factors with stroke in the unmatched cohort

\begin{tabular}{|c|c|c|c|c|c|c|}
\hline \multirow[b]{2}{*}{ Factor } & \multicolumn{3}{|c|}{ Univariate } & \multicolumn{3}{|c|}{ Multivariate } \\
\hline & OR & $\mathbf{9 5} \% \mathbf{C I}$ & $\begin{array}{c}P \\
\text { value }\end{array}$ & OR & $95 \% \mathrm{CI}$ & $\begin{array}{c}P \\
\text { value }\end{array}$ \\
\hline BITA grafting & 0.53 & $0.20-1.39$ & .19 & & & \\
\hline Age per 1-SD increase & 1.28 & $0.85-1.93$ & .23 & & & \\
\hline BMI per 1-SD increase & 0.72 & $0.54-0.97$ & .03 & & & \\
\hline Male & 1.33 & $0.45-3.87$ & .61 & & & \\
\hline Hemoglobin $\mathrm{A}_{1 \mathrm{c}}>7.5 \%$ & 2.15 & $1.09-4.24$ & .03 & 2.38 & $1.06-5.34$ & .04 \\
\hline \multicolumn{7}{|l|}{ GFR } \\
\hline$>60$ & 1 & & & 1 & & \\
\hline $30-60$ & 1.17 & $0.37-3.70$ & .66 & & & \\
\hline$<30$ & 2.31 & $1.10-4.85$ & .03 & & & \\
\hline Hypertension & 2.03 & $0.76-5.40$ & .15 & & & \\
\hline Peripheral arterial disease & 1.89 & $0.82-4.37$ & .13 & & & \\
\hline Cerebral vascular disease & 2.88 & $1.24-6.70$ & .01 & 2.54 & $1.01-6.39$ & .05 \\
\hline LV ejection fraction $<40 \%$ & 0.76 & $0.28-2.03$ & .58 & & & \\
\hline Prior myocardial infarction & 1.47 & $0.68-3.16$ & .33 & & & \\
\hline Heart failure & 4.34 & $1.88-9.99$ & .01 & & & \\
\hline Manipulation of the aorta & 2.32 & $1.30-4.14$ & .01 & 2.71 & $1.10-6.68$ & .02 \\
\hline OT per 1-SD increase & 1.20 & $0.81-1.78$ & .42 & & & \\
\hline BITA grafting* GFR & & & & & & .20 \\
\hline
\end{tabular}

TABLE E5. Causes of death in the matched cohort

\begin{tabular}{lcc}
\hline \multicolumn{1}{c}{ Cause } & SITA group & BITA group \\
\hline No. patients & 412 & 412 \\
Cardiac death & 30 & 11 \\
$\quad$ Myocardial infarction & 8 & 2 \\
Heart failure & 20 & 7 \\
Sudden death & 3 & 1 \\
Noncardiac death & 42 & 27 \\
Infection & 12 & 6 \\
Pulmonary failure & 7 & 5 \\
Hepatic failure & 4 & 1 \\
Aneurysm rupture & 0 & 2 \\
Cancer & 8 & 7 \\
Stroke & 7 & 5 \\
Enteropathy & 4 & 1 \\
\hline
\end{tabular}

SITA, Single internal thoracic artery; BITA, bilateral internal thoracic artery.

TABLE E6. Multivariate Cox proportional hazard models for the association of patient factors with all-cause and cardiac-related mortality, for unmatched patients with GFR $<60 \mathrm{~mL} / \mathrm{min} / 1.73 \mathrm{~m}^{2}$

\begin{tabular}{llll}
\hline \multicolumn{1}{c}{ Factor } & HR & $\mathbf{9 5} \%$ CI & $\boldsymbol{P}$ value \\
\hline All-cause mortality & & & \\
BITA grafting & 0.59 & $0.42-0.85$ & .01 \\
Age per 1-SD increase & 1.38 & $1.13-1.68$ & .01 \\
End-stage renal failure & 3.49 & $2.38-5.12$ & .01 \\
Peripheral arterial disease & 2.26 & $1.57-3.25$ & .01 \\
Prior myocardial infarction & 1.76 & $1.24-2.50$ & .01 \\
Heart failure & 1.61 & $1.02-2.52$ & .04 \\
BITA grafting* GFR & & & .55 \\
Cardiac-related mortality & & & \\
BITA grafting & 0.39 & $0.21-0.72$ & .01 \\
End-stage renal failure & 6.80 & $3.74-12.37$ & .01 \\
Peripheral arterial disease & 2.45 & $1.34-4.47$ & .01 \\
Prior myocardial infarction & 2.58 & $1.42-4.69$ & .01 \\
BITA grafting* GFR & & & .35 \\
\hline HR, Hazard ratio; $C I$, confidence interval; BITA, bilateral internal thoracic artery; $S D$, \\
standard deviation; GFR, glomerular filtration rate. *Indicates interaction term for \\
BITA grafting and GFR which is included in multivariate models.
\end{tabular}

